\title{
Determination of 18-month fuel cycle parameters for the purpose of fuel costs minimization at the basis of use constructions of fuel assemblies in VVER-1200 reactors*
}

\author{
Taha M. Hashlamoun ${ }^{1}$, Sergey B. Vygovsky ${ }^{1}$, Sergey T. Leskin ${ }^{2}$, A. Safa Duman ${ }^{2}$ \\ 1 National Research Nuclear University «MEPhI» (Moscow Engineering Physics Institute), 31 Kashirskoe sh., Moscow, 115409 Russia \\ 2 Obninsk Institute for Nuclear Power Engineering, NRNU «MEPhI», 1 Studgorodok, Obninsk, Kaluga reg., 249040 Russia \\ Corresponding author: Sergey B. Vygovsky (vigovskii@mail.ru)
}

Academic editor: Yury Korovin • Received 12 November 2018 • Accepted 20 January 2019 • Published 20 March 2019

Citation: Hashlamoun TM, Vygovsky SB, Leskin ST, Duman AS (2019) Determination of 18-month fuel cycle parameters for the purpose of fuel costs minimization at the basis of use constructions of fuel assemblies in VVER-1200 reactors. Nuclear Energy and Technology 5(1): 9-15. https://doi.org/10.3897/nucet.5.33976

\begin{abstract}
This article presents the results of research, that were focused on determining the optimal parameters of the extension of (reactor life-time) reactor fuel cycle in order to reduce the total operating costs of nuclear power plants during the transition from 12-month reactor fuel cycle to 18-month fuel cycle.

The relevance of the research is related to the fact that, in recent years, there is a transition at all operating nuclear power plants VVER-1000 (1200) from 12-month reactor fuel cycle to extended 18-month fuel cycle. At the same time, represent the interests to solve the problem of conservation the extension of reactor life-time while reducing the number of loaded fuel assemblies with fresh fuel assemblies, which would reduce the total operating, and fuel costs. Search for solutions of this problem is associated with mandatory implementation of all requirements for the safe operation of the reactor and the reduction of the maximum fast neutron fluence on the reactor vessel in comparison with its value at the operating nuclear power plants.

In the present work, with using the program PROSTOR software complex researched the neutron-physical characteristics of the core at the nominal parameters of the VVER-1200 reactor through the implementation of various fuel cycle strategies. The article developed various schemes of fuel-reloading for an 18-month fuel cycle with a different number of fuel assemblies. The article carries out a comparative analysis of the main parameters in the core for fuel-reloading schemes options of an 18- and 12-month fuel cycle with each other. Determine the minimum amount of fuel assemblies and provide the necessary duration of the reactor life-time for 18-month fuel cycle with using the extension of reactor life-time by reducing the power at the end of the reactor cycle to $70 \%$ of the nominal power. In the article, the arrangements of fuel assemblies were developed to provide limitations of local power by volume of the core, which reduce the fluence of fast neutrons on the reactor vessel in comparison with the projected value of the fluence. This article shows that the 18-month fuel cycle for the VVER-1200 reactor is more economical than the 12-month fuel cycle. These studies were carried out for the VVER-1200 reactor at the power of $100 \%$ of the nominal.
\end{abstract}

* Russian text published: Izvestiya vuzov. Yadernaya Energetika (ISSN 0204-3327), 2018, n. 3, pp. 113-124. 


\section{Keywords}

PROSTOR; fluence; VVER-1000; fuel-reloading scheme; 18-month fuel cycle; effective days; natural days; fuel enrichment; burn-up; operating costs; reactor vessel

The purpose of this research was to determine the reactor refuelings with corresponding to fuel-reloading schemes for the 18-month fuel cycle at the basis of use constructions of fuel assemblies in VVER-1200 reactors (Vygovsky et al. 2013, Leskin et al. 2011, Malygin 2001), which maximally will reduce the total operating costs of nuclear power plants, including fuel costs. Research was carried out on change the fluence of fast neutrons on the reactor vessel (Yanovsky et al. 2011) and verification of fulfill all requirements for ensuring thermal safety of the core (Vygovsky et al. 2011) were performed simultaneously.

It was necessary to determine the minimum number of fuel assemblies to provide the extension of reactor life-time for the one-an-a-half-year long fuel cycle when using elongation reactor life-time, by reducing the power at the end of the campaign to $70 \%$ of the nominal power, and such an arrangement of fuel assemblies, which will provide local power limitations on the core volume. Additional purpose of this research was the examination of the possibility of reduction of neutron fluence on the reactor vessel as compared with the value of fluence currently observed on operated VVER-1200 NPPs (RB-007-99 1999, RB-018-01 2001).

The fuel cycle of nuclear power plants with a VVER reactor touches many aspects related to reactor physics, technologies of uranium mining, enrichment, fabrication of fuel rods (fuel pins) and fuel assemblies (bundles) for loading the reactor core, their transportation, fuel storage and re-processing. Accent was placed in the present research of the possibility of reducing the total operating costs of NPP for extended fuel campaigns during the transition from the 12-month fuel cycle to the 18-month due to a decrease in the number of fresh loaded fuel assemblies (Dementiev 1990, Molchanov 2009).

A formula was suggested in (Hashlamoun and Vygovsky 2018) for estimating relative operating costs, including fuel costs as compared with costs for a 12-month fuel cycle. Derivation of the formula was based on the large scope of data taken from (Kharitonov 2007, Tomas 2005, OECD 1999).

$$
K_{G C}=\frac{1+\alpha \frac{32}{T_{e f f}}+\beta_{0} \frac{N_{\text {rel }} N_{F A} M_{\text {fuel } 0}}{N_{\text {rel0 }} N_{F A} M_{\text {fuel }}}\left(0.7+0.3 \frac{n \%}{n_{0} \%}\right) \frac{\Delta T}{T_{e f f}}}{1+\alpha \frac{32}{T_{\text {effo }}}+\beta_{0} \frac{\Delta T_{0}}{T_{\text {effo }}}},
$$

where $\alpha$ is the fraction of operating costs during the period of scheduled repairs relative to the costs during power operation of the power unit, $\alpha>1$ due to dose commitments during scheduled repairs; b0 is the value of the fuel cost coefficient relative to general operating costs $(\mathrm{b} 0<1)$; $\mathrm{Nrel}$ is the number of fuel-reloading operations for the case of continuous operation of the power unit with 18-month fuel cycle $(\mathrm{Nrel}=60)$; Nrel0 is the number of fuel-reloading operations for continuous operation of the power unit with 12-month fuel cycle (Nrel0 = 40); NFA is the standard number of fresh fuel assemblies used during reloading for 18-month fuel cycle; NFA0 is the standard number of fresh fuel assemblies used during reloading for 12-month fuel irradiation cycle; Mfuel is the mass of fuel in one fuel assembly the projected; Mfuel0 is the mass of fuel in one fuel assembly for operated NPPs with VVER-1200; $\mathrm{n} \%$ is the enrichment of uranium-235 of fuel the projected; $\mathrm{n} 0 \%$ is the enrichment ofuranium-235 of fuel used on operated NPPs; Teff is the duration of the fuel campaign of the reactor at the base power with the parameters of the 18-month fuel cycle for operated NPPs with VVER-1200; Teff0 is the duration of the fuel campaign of the reactor at the base power with the parameters of the 12-month fuel cycle for operated NPPs with VVER-1200; DT0 is the calendar period with taking into account the duration of scheduled repairs for the 12-month fuel cycle (Tcal0 $+\Delta$ Trep, days); $\Delta \mathrm{T}$ is the calendar period with taking into account the duration of scheduled repairs for the 18-month fuel cycle (Tcal $+\Delta$ Trep, days); $\Delta$ Trep is the duration of scheduled repairs, DTrep $\approx 32$ days; and the ratio Teff/DT characterizes the NPP installed capacity utilization factor (ICUF).

The above formula differs from common formula in references (Kharitonov 2007, Tomas 2005, OECD 1999), but, nevertheless, it reflects as a whole all separate components of operating costs for NPPs. Since we are interested in the relative variation of costs, the uncertainty introduced by this formula is not so significant for obtaining the estimations.

Life time of vessel of reactor at base power is constant and unchanging value for different fuel cycles. The projected operability period of reactor vessel is equal to 60 - 70 calendar years for different operating conditions (Semchenkov et al. 2011, Baturin and Vygovsky 2001). For 12-month (four-year) fuel cycle $N_{\text {rel0 }}=60$, while the number of fresh fuel assemblies loaded in the reactor core during every reloading is equal to 42 . Mass of uranium metal in each fuel assembly is equal to $470 \mathrm{~kg}$ and average fuel enrichment is equal to a $4.79 \%$. For 18 -month (four-year) fuel cycle the value $N_{\text {rel }}=40$, while the number of fresh fuel assemblies loaded in the reactor core during every projected reloading is equal to 72 .

For the projected fuel load, the average enrichment of loaded fuel is equal for NPP with VVER-1200 to $4.68 \%$ for the 18-month fuel cycle. Mass of uranium metal in 
each fuel assembly amounts is approximately the same value as that for 12-month fuel cycle. Alternative options with excellent fuel-reloading schemes (with loading 67 fresh fuel assemblies instead of 72) were examined. Fuel-reloading schemes differed from each other with respect to the arrangement of fuel assemblies on the periphery of the reactor core. In one case, residence of spent fuel assemblies of the third-year and two fresh fuel assemblies were placed on the core periphery, and in the second case, residence only spent fuel assemblies of the second-year and third-year were placed on the core periphery (Mastepanov 2009, Zhimerin 1978).

Calculations of neutronics parameters for different options of refueling fuel-reloading schemes were performed using PROSTOR software complex, which is certified by the supervisory authorities of the Russian Federation and demonstrating documented characteristics at the level of standard service software supporting operation of equipment on NPPs with VVER-1200 reactors (Zhimerin 1978, Budnikova et al. 2004).

The option of using 67 fuel assemblies, with arrangement on the reactor core periphery of two fresh fuel assemblies and spent fuel assemblies of the third-year on the reactor core periphery was chosen. The option of using only spent fuel assemblies on the core periphery was rejected because of incompatibility with thermal engineering safety requirements for the reactor core.

In this article presents the results of comparison of main parameters of the reactor core for stationary refuelings, which were calculated for the projected data for 12-month, for 18-month cycles and for the selected alternative fuel-reloading schemes with using 67 fuel assemblies during loading fresh fuel. The following parameters were considered in the analysis of reactor core safety and estimated given operating costs:

- $D N B R_{\min }$ - The minimum departure from nuclear boiling ratio;

- $\max \left(Q L-0.98 \cdot Q L_{\text {lim }}\right)-$ The maximum difference between the calculated-measured and limiting values of linear fuel rod per unit length (must be $<0$ );

- $K Q_{\max }-$ The maximum irregularity factor of a power of fuel assembly power over the reactor core;

- $K V_{\max }$ - The maximum irregularity factor of power release over the core volume;

- average fuel burnup values during fuel irradiation campaign for peripheral fuel assemblies (for the purpose of comparison of the values of fast neutron fluence on the reactor vessel for different options);

- average values of the fuel burnout for the discharged fuel;

- average values of the fuel burnout per campaign in peripheral fuel assemblies (to compare values of fluence of fast neutrons on the reactor vessel different options);

- the maximum (average) values burnup for the discharged fuel;

- the maximum burnup values of fuel in fuel rod in the discharged fuel;
- the maximum burnup values for fuel pellet in fuel rods in the discharged fuel.

Determining estimated variation of fast neutron fluence on reactor vessel for different core loading options is required for performing comprehensive comparison. Straightforward methodology for estimating this variation suggested in (Vygovsky et al. 2013) contains base azimuthal distribution of fast neutrons with energies above $0.5 \mathrm{MeV}$ on the inner surface of reactor vessel for serial VVER-1000 obtained using DORT software (Rhoades and Childs 1988):

For a full comparison, it is necessary to make assessments of changes the fluence of fast neutrons on the reactor vessel for different options. in (Vygovsky et al. 2013) contains base azimuthal distribution of fast neutrons with energies above $0.5 \mathrm{MeV}$ on the inner surface of reactor vessel for VVER-1000, which found by using the DORT program (Rhoades and Childs 1988), a simple method for assessment this change was proposed:

$$
\frac{\Phi_{\mathrm{var}}\left(\theta_{i}\right)}{\Phi_{0}\left(\theta_{i}\right)} \approx \frac{d b_{\mathrm{var} i}}{d b_{0 i}},
$$

where $i=1,2, \ldots, 7 ; \mathrm{q}_{1}=0^{\circ}, \mathrm{q}_{2}=7.59^{\circ}, \mathrm{q}_{3}=16.10^{\circ}$, $\theta_{4}=25.29^{\circ}, \theta_{5}=34.72^{\circ}, \theta_{6}=44.84^{\circ}, \theta_{7}=52.41^{\circ} ; F_{\text {var }}\left(q_{i}\right)$ is the azimuthal distribution of fast neutrons on the inner surface of reactor vessel in the most vulnerable places for the refueling for considered option; $\mathrm{F}_{0}\left(\mathrm{q}_{i}\right)$ is the base azimuthal distribution of fast neutrons on the inner surface of reactor vessel of VVER-1000 reactor in the most vulnerable places; $d b_{\text {vari }}$ is the variation of burnup in $i$-th peripheral fuel assembly during the period of operation of the refueling between consecutive fuel-reloading operations within the $60^{\circ}$ symmetry segment for the option under examination; $d b_{0 i}$ is the variation of fuel burnup in the $i$-th peripheral fuel assembly during the period between consecutive fuel-reloading operations within the $60^{\circ}$ symmetry segment for the base option for operated NPPs;

The condition for ensuring lifetime of reactor vessel equipment for the projected is following:

$$
\frac{\Phi_{\mathrm{var}}\left(\theta_{i}\right)}{\Phi_{0}\left(\theta_{i}\right)} \approx \frac{d b_{\mathrm{var} i}}{d b_{0 i}}<1 .
$$

Taking into consideration the 60-degree symmetry of the reflector surrounding the core it is sufficient to verify satisfaction of the above inequation for peripheral fuel assemblies within the segment.

Figures 1, 2 show fuel-reloading schemes and fuel load maps for the selected alternative fuel-reloading implementation of the 18-month cycle option and for the projected option of the 18-month cycle.

The examined options ensured the local power limitations on the core volume within the volume of the reactor core and the minimum departure from nuclear boiling ratio DNBR more than 1.35. irregularity factor of a power of fuel assembly power over the reactor core does not exceed 1.4 for all options (Figs. 3-6).

Figure 7 shows the dependence of the ratio of the given costs coefficient to the dose commitments at different 


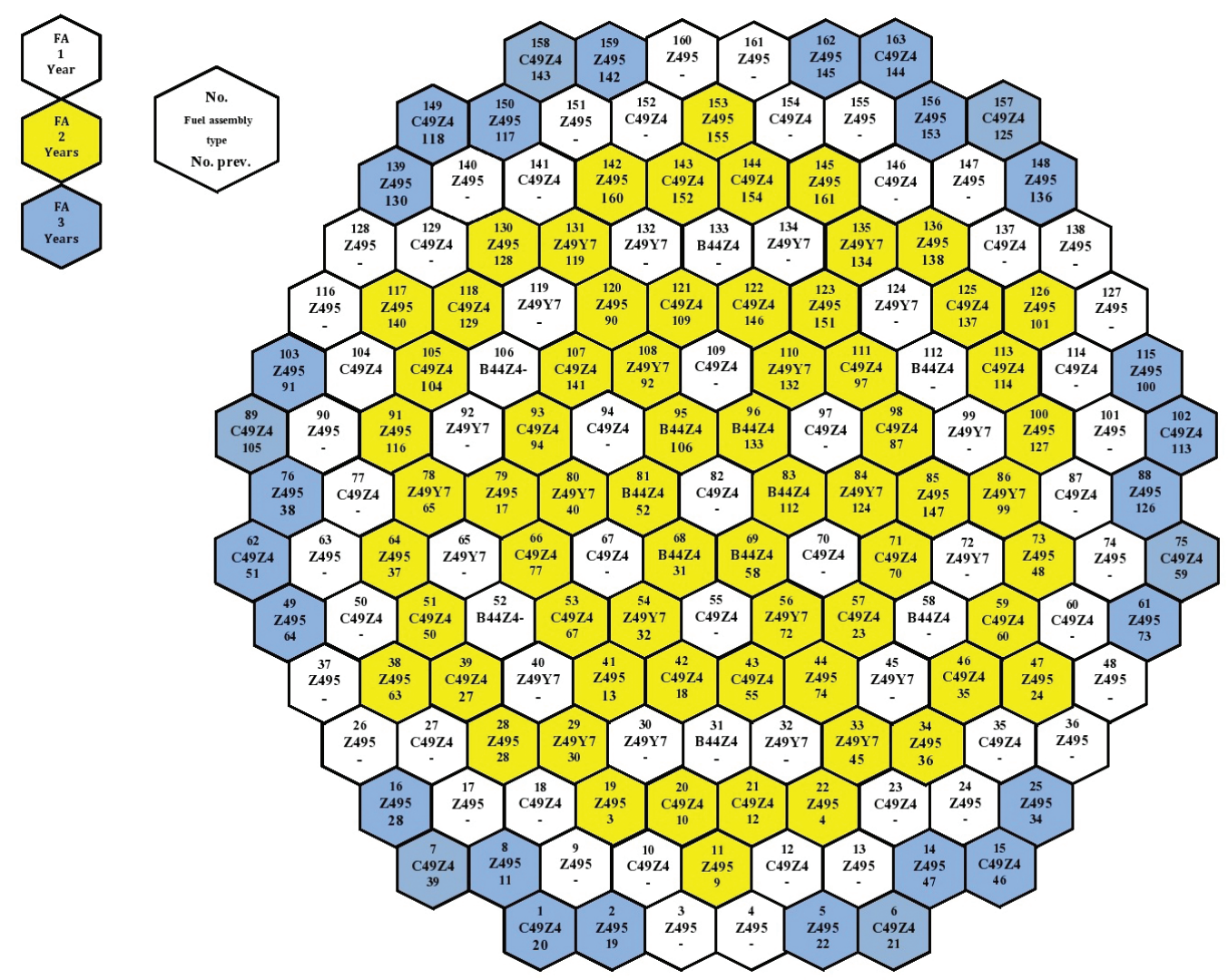

Figure 1. Map for the selected alternative fuel-reloading for the 18-month fuel cycle (67 fuel assemblies, $3200 \mathrm{MW}$ )

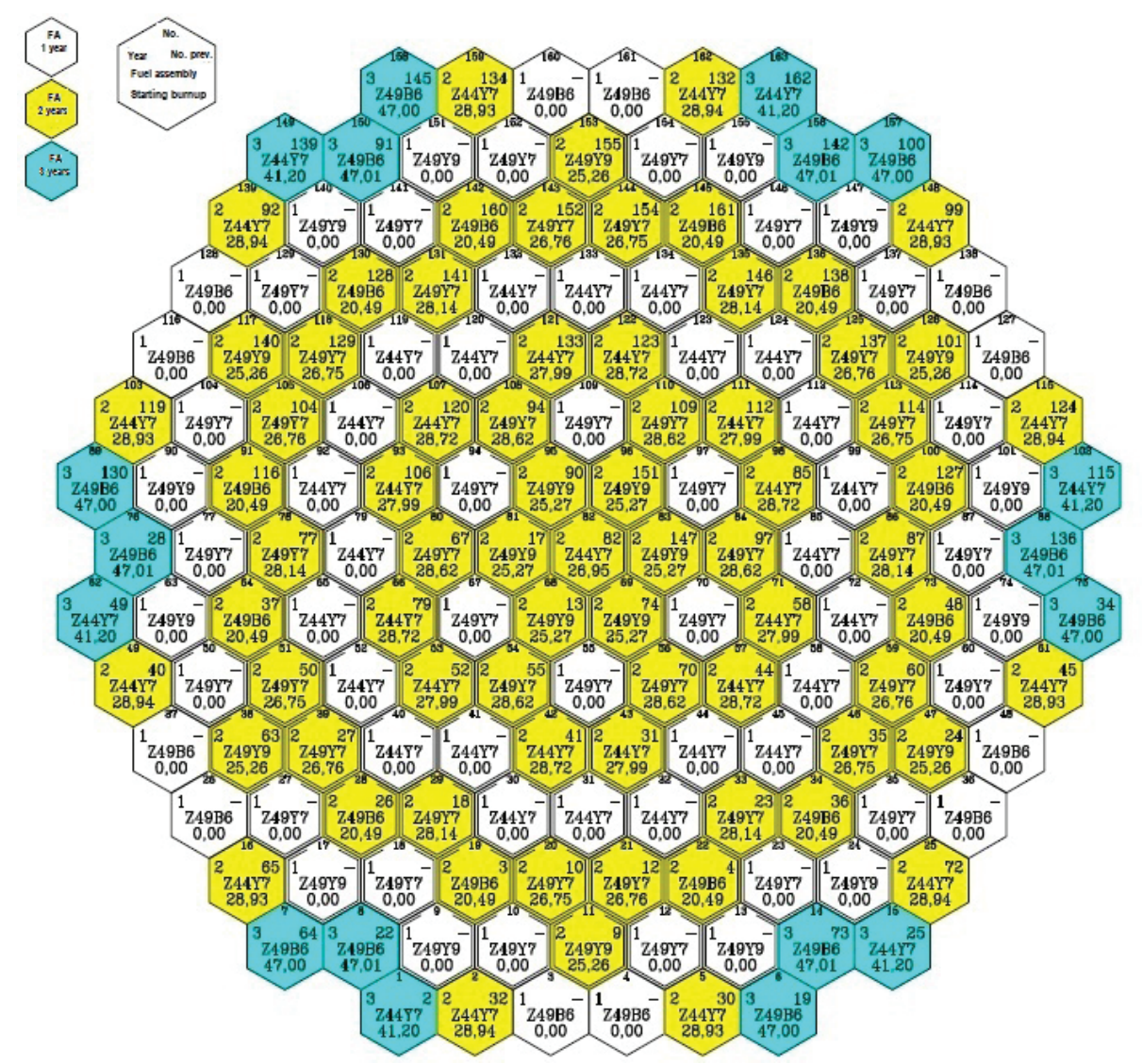

Figure 2. Map for the design fuel load for the 18-month fuel cycle (72 fuel assemblies, $3200 \mathrm{MW}$ ) 


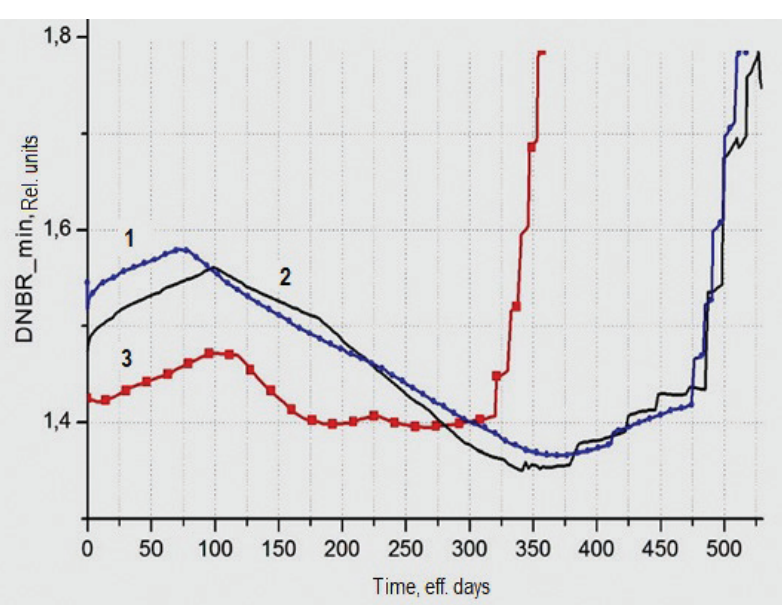

Figure 3. Dependence of $D N B R_{\min }$ on time for the case of stationary fuel burnup campaign: 1 - project 12 -months extended fuel cycle; 2 - project 18 -month extended cycle; 3 - alternative 18-month cycle

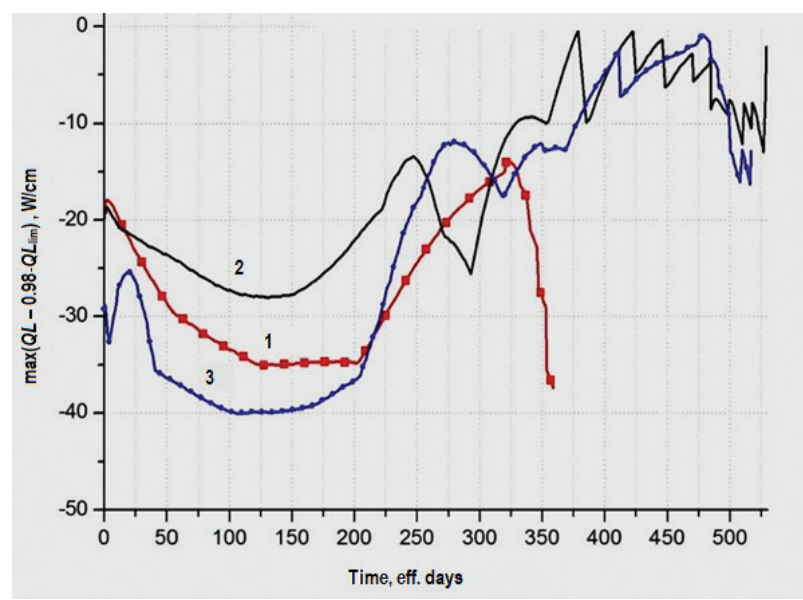

Figure 5. Time-dependence of $\max \left(Q L-0.98 \cdot Q L_{\mathrm{lim}}\right)$ for the case of stationary fuel burnup campaign: 1 - project 12 -month extended fuel cycle; 2 - project 18 -month extended cycle; 3 alternative 18-month cycle

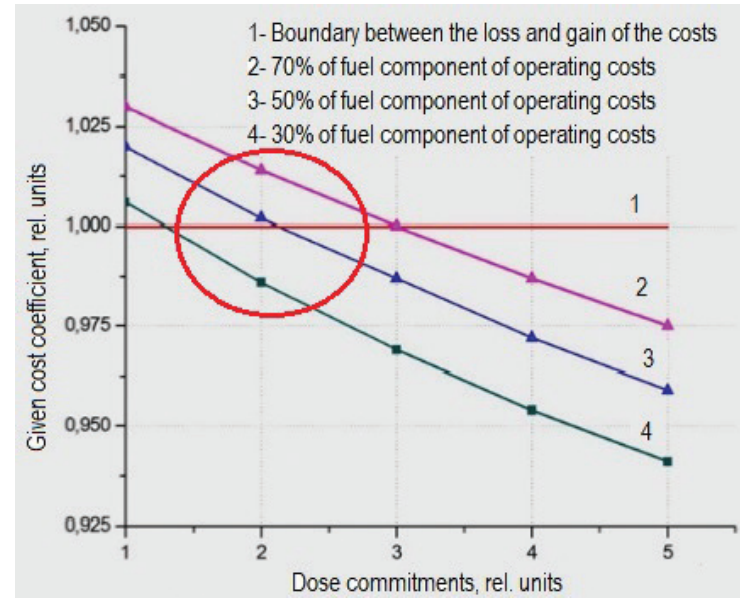

Figure 7. Dependence on the given value of dose commitments of gevin cost coefficient for the 18-month fuel cycle relative to the costs for 12-month cycle for the project option of fuel-reloading option and fuel-reloading scheme

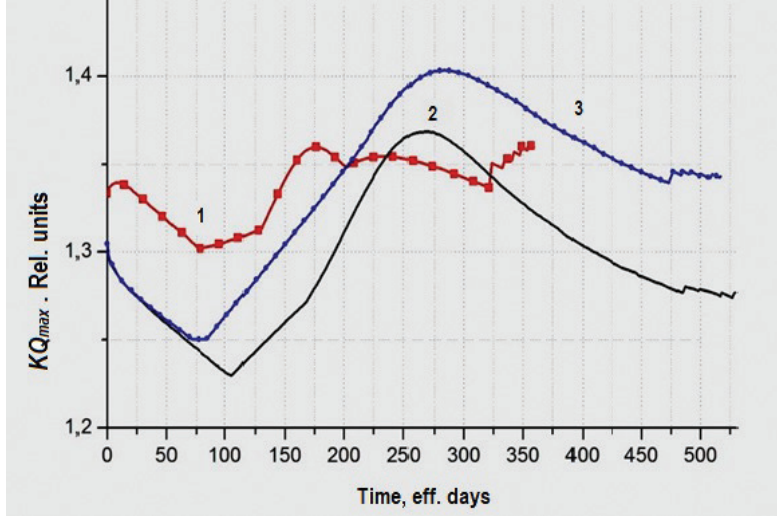

Figure 4. Time-dependence of $K Q_{\max }$ for the case of stationary fuel burnup campaign: 1 - project 12 -month extended fuel cycle; 2 - project 18-month extended cycle; 3 - alternative 18 -month cycle

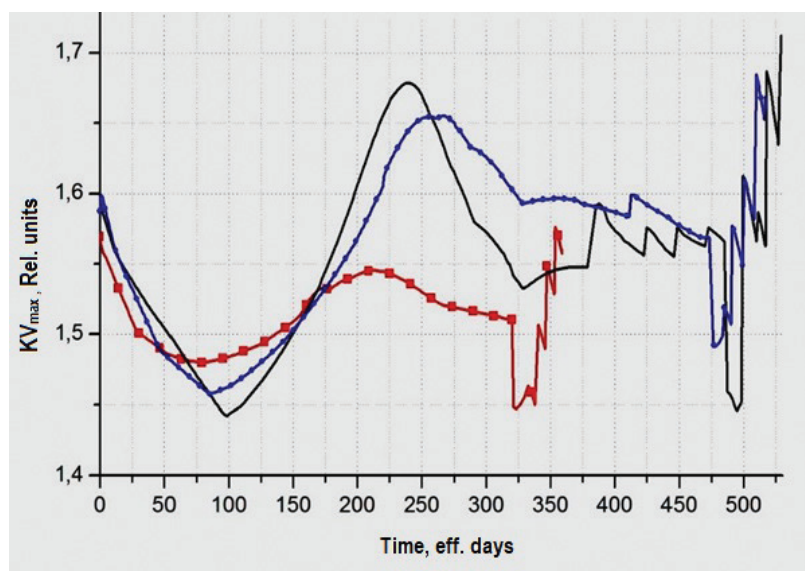

Figure 6. Time-dependence of $K V_{\max }$ for the case of stationary campaign of fuel burnup: 1 - project 12 -months extended fuel cycle; 2 - project 18 -month extended cycle; 3 - alternative 18-month cycle

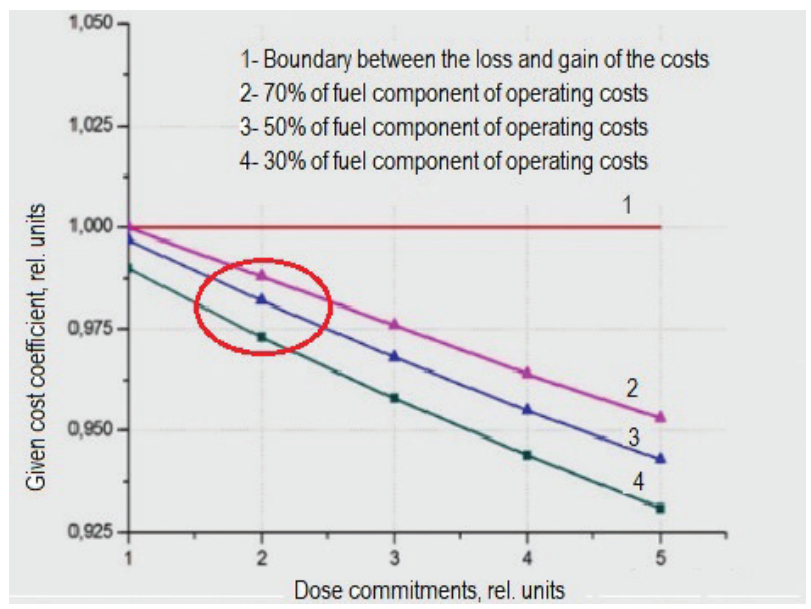

Figure 8. Dependence on the given value of dose commitments of given cost coefficient for the 18-month fuel cycle relative to the costs for 12-month cycle for the alternative option of fuel-reloading option and fuel-reloading scheme 
values of the fuel component of operating costs for the projected option for the implementation of the 18-month fuel cycle with using 72 fresh fuel assemblies according to the standard fuel when refueling in the stationary mode of fuel-reloading.

From the above results, Figure 8 confirms the conclusion that the 18-month cycle for the VVER-1200 reactor is more economical than the 12-month cycle. For the selected alternative fuel-reloading option and fuel-reloading scheme with using 67 fuel assemblies, operating costs are noticeably less than for the projected option when using 72 fuel assemblies.

For the 18-month fuel cycle, all considered refueling options provided a noticeable decrease in the fluence values as compared with the 12-month cycle. More than that, the value of fluence for the alternative refueling option is lower than that for the projected option in the most vulnerable place of reactor vessel (Table 1). It follows from the table that for the selected the alternative refueling option with 67 fuel assemblies, irregularity of burnup for the discharged fuel assemblies is noticeably lower than for the projected fuel-reloading scheme.

The maximum values of fuel burnup in fuel assemblies and in fuel rods for all the examined options are presented in Table 2. It follows from the comparison of these values, that maximum values of fuel burnup are minimal for the alternative refueling option. The obtained results evidence confirms that better use of fuel for in the case of the alternative refueling option.

\section{Conclusion}

Conducted research allowed to determine an alternative (projected scheme) fuel-reloading scheme and to form the stationary refuelings. For found schemes of the fuel-reloading and refuelings of 18-month fuel cycle with regard to all main characteristics of the reactor core show advantages as refers to the following:

- Average fuel burnup for the discharged fuel;

- Equability of the fuel burnup for the discharged fuel;

- Value of fast neutron fluence in the most vulnerable places of reactor vessel;

- Value of given operating costs with maximum dispersion of its separate components.

Thermal engineering safety of reactor core was substantiated For found the fuel-reloading schemes and stationary refuelings. All main parameters characterizing

Table 1. Distribution of average values of power generation for fuel assemblies in the peripheral layer within the reactor core segment $60^{\circ}$ for the projected and alternative options of stationary refueling, which determines the fast neutron fluence on the reactor vessel

\begin{tabular}{|c|c|c|c|c|c|c|c|c|}
\hline \multicolumn{2}{|c|}{$\begin{array}{l}\text { Angle from zero line at which the center of the next periph- } \\
\text { eral fuel assembly is positioned, qi, }{ }^{\circ}\end{array}$} & 0 & 7.59 & 16.10 & 25.29 & 34.72 & 44.84 & 52.41 \\
\hline \multirow{2}{*}{$\begin{array}{l}\text { Power generation during } \\
\text { the campaign of the } \\
\text { peripheral fuel assembly } \\
\text { relative to its fuel mass, }\end{array}$} & $\begin{array}{l}\text { Projected fuel-reloading scheme, } \\
3200 \text { MW ( } 42 \text { FAs) }\end{array}$ & 18.95 & 10.40 & 10.71 & 23.45 & 23.45 & 10.71 & 6.29 \\
\hline & $\begin{array}{l}\text { Projected fuel-reloading scheme, } \\
3200 \text { MW ( } 72 \text { FAs) }\end{array}$ & 12.11 & 6.82 & 11.41 & 19.88 & 19.89 & 11.42 & 6.98 \\
\hline $\begin{array}{l}\Delta B n\left(\mathrm{q}_{i}\right) \\
\mathrm{MW} \cdot \mathrm{day} / \mathrm{kg}\end{array}$ & $\begin{array}{l}\text { Alternative fuel-reloading } \\
\text { scheme, } 3200 \mathrm{MW} \text { (67 FAs) }\end{array}$ & 11.66 & 6.06 & 9.93 & 19.97 & 19.97 & 9.93 & 6.05 \\
\hline
\end{tabular}

Table 2. Values of fuel burnup in fuel assemblies and in fuel rods and the extended of reactor campaign for different options of stationary refueling

\begin{tabular}{lccc}
\hline $\begin{array}{l}\text { Type of reactor refuelings and fuel-reloading } \\
\text { schemes }\end{array}$ & $\begin{array}{c}\text { 12-month extended } \\
\text { cycle (42) }\end{array}$ & $\begin{array}{c}\text { 18- month extended } \\
\text { cycle (72) }\end{array}$ & $\begin{array}{c}\text { 18- month extended } \\
\text { cycle (67) }\end{array}$ \\
\hline $\begin{array}{l}\text { Average burnup for discharged fuel, } \\
\text { MW·day / kg U }\end{array}$ & 57.94 & 50.40 & 52.86 \\
$\begin{array}{l}\text { Maximum burnup (averaged for fuel assembly) of } \\
\text { discharged fuel, MW·day / kg U }\end{array}$ & 64.71 & 58.21 & 65.63 \\
$\begin{array}{l}\text { Maximum burnup in fuel rod in the discharged } \\
\text { fuel, MW·day / kg U }\end{array}$ & 71.19 & 65.20 & 70.13 \\
$\begin{array}{l}\text { Maximum burnup for fuel pellet in fuel rod } \\
\text { discharged fuel from the core, MW·day / kg U }\end{array}$ & 78.93 & 70.13 & 528 \\
$\begin{array}{l}\text { Duration of operation of the refueling for the case } \\
\text { of extended reactor campaign with reactor power } \\
\text { reduced to 70\%, eff. days }\end{array}$ & 367 & 539 & \\
\hline
\end{tabular}


reactor core safety are within the limits of permissible values according to the data provided by the Chief Designer.

\section{References}

- Anokhin AYu, Tsibulsky VF, Davidenko VD (2001) The UNK program complex for detailed calculation of the neutron spectrum in nuclear reactors. Moscow. Report of NRC «Kurchatov Institute». Inventory no. 35-410-4/81, May 18. [in Russian]

- Baturin DM, Vygovsky SB (2001) Accounting for the spectral history of burnup in the preparation of neutron-physical constants of VVER-1000 fuel assemblies. Atomnaya energiya, 90(4): 256-260. [in Russian]. https://doi.org/10.1023/A:1011369130707

- Budnikova OA, Vygovsky SB, Zimin VG, Korikovsky KP, Krayushkin YuA, Mischerin SA, Osadchy MA, Semyonov AA, Strashnykh VP, Chernov EV, Chernakov VA (2004) PROSTOR Software Complex (Ver. 1). The Appendix to the Certification Passport no. 182 dated October 28. [in Russian]

- Dementiev BA (1990) Nuclear Power Reactors. Training manual for universities. Moscow. Energoizdat Publ., 352 pp. [in Russian]

- Hashlamoun TM, Vygovsky SB (2018) Study of the possibility of increasing the cost efficiency of nuclear fuel usage at NPP with VVER1000 reactor for 18-month fuel cycle. Yadernaya fizika i inzhiniring. [in Russian]

- Kharitonov VV (2007) Power Engineering. Technical and Economic Fundamentals. Moscow. NRNU MEPhI Publ., 256 pp. [in Russian]

- Leskin ST, Shelegov AS, Slobodchuk VI (2011) Physical features and design of the VVER-1000 reactor. Moscow. NRNU MEPhI Publ., 116 pp. [in Russian]

- Malygin VB (2001) Fuel cycle of power reactors and problems of increasing the resource of fuel elements. Moscow. NRNU MEPhI Publ., 84 pp. [in Russian]

- Mastepanov AM (2009) The Fuel and Energy Complex of Russia at the Turn of the Century: The Status of the Problem and the Prospects for Development. Vol. 1. Moscow. Energoatomizdat Publ., 477 pp. [in Russian]

- Molchanov VL (2009) Nuclear Fuel for NPPs with WWER: Current State and Prospects. Proc. of the VI-th International Conference
It is important to note that the suggested solution can be implemented already at the present moment on the basis of existing project of operated fuel assemblies.
«Ensuring the Safety of NPPs with WWER», May 26-29. Podolsk. JSC «OKB «Gidropress» Publ. [in Russian]

- OECD (1999) The Economics of the Nuclear Fuel Cycle. Nuclear Energy Agency. Moscow. Energoizdat Publ., 141 pp. [in Russian]

- RB-007-99 (1999) Allowance for the fluence of fast neutrons on VVER shells and test specimens for the subsequent prediction of the radiation resource of the hulls. Vestnik Gosatomnadzora Rossii, 1(5): 2-14. [in Russian]

- RB-018-01 (2001) Method of neutron control on the external surface of the hulls of light water power reactors of nuclear power plants. Vestnik Gosatomnadzora Rossii, 6(19): 32-47. [approved on 17.12.2001]. [in Russian]

- Rhoades WA, Childs RL (1988) The DORT Two-Dimensional Discrete Ordinate Transport Code. Nucl.Sci. \& Eng., 99(1): 88-89. https://doi.org/10.13182/NSE88-A23547

- Semchenkov Yu, Pavlovichev A, Chibinyaev A (2011) Proximity to the scenario. Prospects for evolutionary development of VVER fuel. Atomnaya energetika Rossii, 10: 25-29. [in Russian]

- Tomas S (2005) Nuclear Energy: Myth and Reality. Ekonomika Yadernoy Energetiki, 5: 47. [in Russian]

- Vygovsky SB, Ryabov NO, Chernov EV (2011) Safety and tasks of engineering support for the operation of NPPs with VVER. Moscow. NRNU MEPhI Publ., 376 pp. [in Russian]

- Vygovsky SB, Ryabov NO, Semenov AA, Chernov EV, Bogachek LN (2013) Physical and structural features of nuclear power plants with VVER. Moscow. NRNU MEPhI Publ., 304 pp. [in Russian]

- Yanovsky SE, Yeremenko ML, Ovdiyenko YuN (2011) Development of approaches to sensitivity analysis of the neutron fluence calculation model for VVER reactors on the basis of DOORS code complex. Yadernaya i radiatsionnaya bezopasnost', 3(51): 38-43. [in Russian]

- Zhimerin DG (1978) Problems of the Development of Power Engineering. Moscow. Energiya Publ., 288 pp. [in Russian] 